Check for updates

Cite this: RSC Adv., 2017, 7, 42225

Received 26th July 2017

Accepted 24th August 2017

DOI: $10.1039 / c 7 r a 08244 d$

rsc.li/rsc-advances

\section{Novel 1,2,3-triazolium-functionalized inulin derivatives: synthesis, free radical-scavenging activity, and antifungal activity}

\begin{abstract}
Qing Li, ${ }^{a}$ Lishushi Qiu, ${ }^{\mathrm{b}}$ Wenqiang Tan, ${ }^{\text {ac }}$ Guodong Gu${ }^{\mathrm{d}}$ and Zhanyong Guo (D) *a
A new class of inulin derivatives possessing 1,2,3-triazolium charged units by associating "click reaction" with efficient 1,2,3-triazole quaternization were designed and synthesized. After the chemical modification, all the inulin derivatives showed good solubility in water, and exhibited excellent bioactivity compared to inulin. In the 1,1-diphenyl-2-picrylhydrazyl (DPPH) radical-scavenging assay, the scavenging activity of 1,2,3-triazolium inulin derivatives $(5 a-5 d)\left(I C_{50} 0.21-0.29 \mathrm{mg} \mathrm{mL}^{-1}\right)$ was found to be higher than that of inulin derivatives $(4 a-4 d)\left(I C_{50} 0.58-0.95 \mathrm{mg} \mathrm{mL}^{-1}\right)$ and inulin. $5 \mathrm{a}-5 \mathrm{~d}\left(\mathrm{IC}_{50}<0.01 \mathrm{mg} \mathrm{mL}^{-1}\right)$ also exhibited stronger inhibitory activity against superoxide anion formation than $4 a-4 d\left(\mathrm{IC}_{50} 0.02-\right.$ $\left.0.09 \mathrm{~m} \mathrm{~g} \mathrm{~mL}^{-1}\right)$ and Vitamin $\mathrm{C}\left(\mathrm{IC}_{50} 0.02 \mathrm{mg} \mathrm{mL}^{-1}\right)$. In the antifungal assays, $5 \mathrm{a}-5 \mathrm{~d}$ also inhibited the growth of tested phytopathogens more effectively with inhibitory indices of $43.10-82.56 \%$ at $1.0 \mathrm{mg} \mathrm{mL}^{-1}$, compared with $4 \mathrm{a}-4 \mathrm{~d}$ and inulin. Based on these data, it is reasonable to propose that the introduction of 1,2,3-triazolium group through chemical modification is significant to enhance the free radical-scavenging activity and antifungal activity of inulin.
\end{abstract}

\section{Introduction}

Inulin is a natural, biodegradable, and plant-derived storage polysaccharide, and has attracted broad attention due to its beneficial nutritional attributes for human health. Inulin also has advantages of non-toxicity, biodegradability, and biocompatibility, facilitating its applications in the food, feed, biofuel, water purification, and pharmaceutical industries. However, application of inulin has been limited due to its low bioactivity. Because the biological activity of a polysaccharide is related with its molecular structure, increasing attention has been paid to chemical modification of polysaccharide structure to improve its biological activity. ${ }^{1-7}$ To promote the antifungal activity of inulin, many inulin derivatives have been prepared such as $O$-(aminoethyl)inulin and 6-amino-6-deoxyinulin by chemical modification. Our previous publications also reported the improved antioxidant activities and antifungal activities of inulin derivatives after chemical modification. ${ }^{8-10}$

Triazole derivatives represent an interesting class of heterocyclic compounds; they possess many biological activities such as antimicrobial, anti-tubercular, anti-inflammatory and

\footnotetext{
${ }^{a}$ Key Laboratory of Coastal Biology and Bioresource Utilization, Yantai Institute of Coastal Zone Research, Chinese Academy of Sciences, Yantai, Shangdong 264003, China. E-mail: zhanyongguo@hotmail.com

${ }^{b}$ School of Chemistry and Chemical Engineering, Yantai University, Yantai 264005, China

${ }^{c}$ Graduate School of Chinese Academy of Sciences, Beijing 100039, China

${ }^{d}$ Alliance Pharma, Inc. 17 Lee Boulevard Malvern, PA 19355, USA
}

anticancer activities. ${ }^{11-15}$ These observations inspired us to modify inulin with thiazolyl as a substituent via "click reaction" to improve its bioactivity. The Huisgen 1,3-dipolar $[3+2]$ cycloaddition of azides and alkynes has emerged as the frontrunner of "click reaction", and this synthetic approach is highly efficient, convenient and the reaction conditions are mild. For example, Ren et al. prepared a novel amphiphilic aminated inulin derivative via "click reaction", and this inulin derivative owned stronger antibacterial property against $S$. aureus than inulin. ${ }^{8}$ Furthermore, 1,2,3-triazole is capable of either losing a proton (acting as a weak acid) or accepting a proton through the nitrogen lone pair of electrons (acting as a weak Brønsted base),${ }^{16,17}$ which might be conducive to scavenging free radicals.

1,2,3-Triazolium cations have recently been developed by quaternization of 1,2,3-triazoles with halogenide. The quaternization of 1,2,3-triazoles could help improve solubility. Meanwhile, the positively charged moiety of the cationic molecules could react with the negatively charged components of fungi and bacteria, which is favorable for the biological activity of the inulin compound. ${ }^{17,18}$ However, there are very few reports on synthesis of inulin derivatives bearing 1,2,3-triazolium cations, and the effect of quaternization of 1,2,3-triazole moieties on the bioactivity of inulin derivative is still unknown.

On the basis of these observations, it was thought of synthesizing a new class of inulin derivatives, wherein 1,2,3triazolium was linked to inulin as substituent. Application of "click reaction" allows us to prepare various inulin based materials via a one-step reaction from azido-inulin and 
terminal alkynes with different substituent groups. And the inulin derivative bearing 1,2,3-triazolium will be obtained by alkylation of 1,2,3-triazolyl inulin derivative. Through the above chemical modifications of inulin, the aimed products would have hydrophilic group (triazole or/and quaternary ammonium salt) and lipophilic group (acetyl), which enabled the target product to have a good surface activity. At the same time triazole is a biologically active group, which could be conducive to improving inulin biological activity. We therefore speculated that the aimed products might have improved biological activity, such as better antioxidant activity and stronger antifungal activity. The free radical-scavenging and antifungal activity of inulin and the synthesized inulin derivatives will be investigated to verify our design of structures.

\section{Experimental}

\subsection{Materials}

Inulin was purchased from E. Merck (Darmstadt, Germany). Its average degree of polymerization is around 20 fructosyl fructose. 3-Pyridinecarboxaldehyde was purchased from Aladdin Chemical Corp (Shanghai, China). Terminal alkynes (propargyl alcohol, 3butyn-1-ol, 4-pentyn-1-ol, and 5-hexyn-1-ol) were purchased from Sigma-Aldrich (Shanghai, China) with a minimum purity of $98 \%$. The other reagents such as iodomethane, sodium iodide, sodium hydroxide, cuprous iodide, potassium iodide, and solvents are analytical grade and were supplied by Sinopharm Chemical Reagent Co., Ltd. (Shanghai, China).

\subsection{Analytical methods}

FT-IR spectra were measured on a Jasco-4100 Fourier Transform Infrared Spectroscopy (JASCO Co., Ltd., Shanghai, China) with $\mathrm{KBr}$ disks. ${ }^{1} \mathrm{H}$ Nuclear Magnetic Resonance $\left({ }^{1} \mathrm{H} \mathrm{NMR}\right)$ was measured with a Bruker AVIII-850 Spectroscopy with TCI CryoProbe (Bruker Tech. and Serv. Co., Ltd., Beijing, China).

\subsection{The synthesis of inulin derivatives}

The synthetic routes for the preparation of inulin derivatives are shown in Scheme 1.

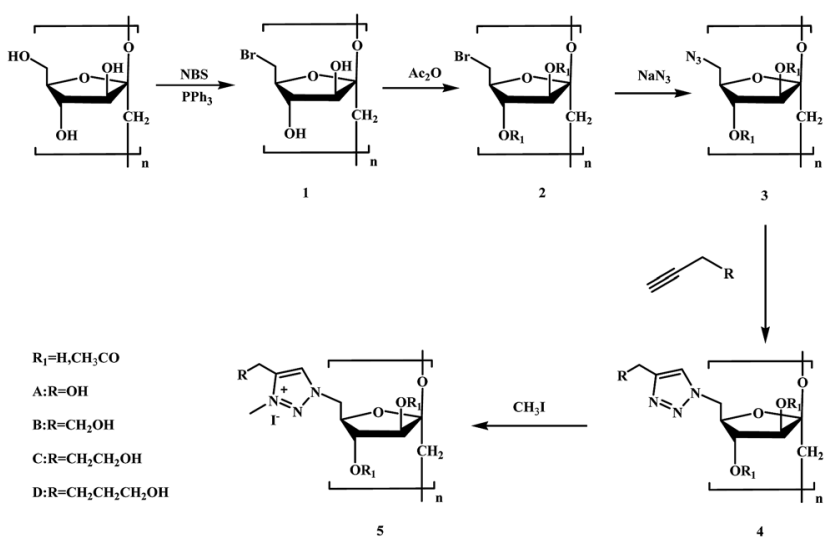

Scheme 1 Synthetic routes for the preparation of inulin derivatives.
Hydrophobic 6-bromo-6-deoxyinulin (2) and hydrophobic 6azido-6-deoxyinulin (3) were prepared according to the methods reported by Ren. ${ }^{8}$

Hydrophobic 6-bromo-6-deoxyinulin (2). ${ }^{1} \mathrm{H}$ NMR (500 MHz, DMSO- $\left.d_{6}\right): \delta 2.02 \mathrm{ppm}\left(\mathrm{CH}_{3}-\mathrm{C}=\mathrm{O}\right), \delta 3.59-5.33 \mathrm{ppm}$ (pyranose rings), $3.95 \mathrm{ppm}\left(\mathrm{CH}_{2} \mathrm{Br}\right)$; FT-IR (thin film): $\nu 1743(\mathrm{C}=\mathrm{O}$ of acetyl).

Hydrophobic 6-azido-6-deoxyinulin (3). Yields: $68.8 \% ;{ }^{1} \mathrm{H}$ NMR (500 MHz, DMSO- $\left.d_{6}\right): \delta 2.01 \mathrm{ppm}\left(\mathrm{CH}_{3}-\mathrm{C}=\mathrm{O}\right), \delta 3.34-$ $5.26 \mathrm{ppm}$ (pyranose rings), $4.0 \mathrm{ppm}\left(\mathrm{CH}_{2} \mathrm{~N}_{3}\right)$; FT-IR (thin film): $\nu$ 2105 (C-6-azido), $\nu 1743$ (C=O of acetyl).

Preparation of compound $4 a-4 d$. A mixture of compound 3 (1.0 mmol), $12 \mathrm{mg}$ cuprous iodide, terminal alkynes $(2.0 \mathrm{mmol})$, and $3 \mathrm{~mL}$ triethylamine in $20 \mathrm{~mL}$ DMSO was stirred at $75^{\circ} \mathrm{C}$ for $48 \mathrm{~h}$ under argon. The mixture was filtered and the filtrate was collected and precipitated into ethanol. The precipitate was washed with saturated solution of potassium iodide and filtered. The unreacted alkyne was extracted in a Soxhlet apparatus with ethanol for two days. The products were dried at $60{ }^{\circ} \mathrm{C}$ for $24 \mathrm{~h}$.

4a. Yield: $62.1 \% ;{ }^{1} \mathrm{H}$ NMR (500 MHz, DMSO- $\left.d_{6}\right): \delta 1.99 \mathrm{ppm}$ $\left(\mathrm{CH}_{3}-\mathrm{C}=\mathrm{O}\right.$ ), $\delta 7.83 \mathrm{ppm}$ (triazole-5-H); FT-IR (thin film): $\nu 3409$ (stretching vibration of $\mathrm{OH}), \nu 1735(\mathrm{C}=\mathrm{O}$ of acetyl), $\nu 786(\mathrm{C}-\mathrm{H}$ of triazole).

4b. Yield: $82.5 \%$; ${ }^{1} \mathrm{H}$ NMR (500 MHz, DMSO- $\left.d_{6}\right): \delta 1.99 \mathrm{ppm}$ $\left(\mathrm{CH}_{3}-\mathrm{C}=\mathrm{O}\right), \delta 2.77 \mathrm{ppm}\left(\mathrm{OH}-\mathrm{CH}_{2}-\mathrm{CH}_{2}\right), \delta 7.77$ ppm (triazole-5H); FT-IR (thin film): $\nu 3424$ (stretching vibration of OH), $\nu 1743$ (C=O of acetyl), $\nu 790$ (C-H of triazole).

4c. Yield: $85.0 \% ;{ }^{1} \mathrm{H}$ NMR (500 MHz, DMSO- $d_{6}$ ): $\delta 1.72 \mathrm{ppm}$ $\left(\mathrm{OH}-\mathrm{CH}_{2}-\mathrm{CH}_{2}-\mathrm{CH}_{2}\right), \delta 1.99 \mathrm{ppm}\left(\mathrm{CH}_{3}-\mathrm{C}=\mathrm{O}\right), \delta 2.63$ ppm $(\mathrm{OH}-$ $\mathrm{CH}_{2}-\mathrm{CH}_{2}$ ), 7.77 ppm (triazole-5-H); FT-IR (thin film): $\nu 3421$ (stretching vibration of $\mathrm{OH}), \nu 2942$ (C-H of methylene), $\nu 1743$ ( $\mathrm{C}=\mathrm{O}$ of acetyl), $\nu 794$ (C-H of triazole).

4d. Yield: $80.3 \% ;{ }^{1} \mathrm{H}$ NMR (500 MHz, DMSO- $\left.d_{6}\right): \delta 1.42 \mathrm{ppm}$ $\left(\mathrm{OH}-\mathrm{CH}_{2}-\mathrm{CH}_{2}-\mathrm{CH}_{2}-\mathrm{CH}_{2}\right), \delta 1.61 \mathrm{ppm}\left(\mathrm{OH}-\mathrm{CH}_{2}-\mathrm{CH}_{2}-\mathrm{CH}_{2}\right)$, $\delta 1.99 \mathrm{ppm}\left(\mathrm{CH}_{3}-\mathrm{C}=\mathrm{O}\right), \delta 2.35 \mathrm{ppm}\left(\mathrm{OH}-\mathrm{CH}_{2}-\mathrm{CH}_{2}\right), \delta 7.72 \mathrm{ppm}$ (triazole-5-H); FT-IR (thin film): $\nu 3424$ (stretching vibration of $\mathrm{OH}), \nu 1743$ (C=O of acetyl), $\nu 798$ (C-H of triazole).

Inulin derivative bearing 1,2,3-triazolium (5) were prepared according to the methods reported by Tan. ${ }^{19}$ A solution of 1,2,3triazole-functionalized inulin derivative (3) (1 $\mathrm{mmol})$ and iodomethane $(0.187 \mathrm{~mL}, 3 \mathrm{mmol})$ in $15 \mathrm{~mL}$ of DMSO was stirred at $60{ }^{\circ} \mathrm{C}$ for $24 \mathrm{~h}$. Afterwards, the remaining iodomethane was evaporated, and the reaction mixture was precipitated into $100 \mathrm{~mL}$ of acetone. The solid product was filtered, washed with acetone three times. After being dialyzed against deionized water for $48 \mathrm{~h}$, the inulin derivative (5) was obtained by lyophilization of the aqueous solution.

5a. Yield: $98.5 \% ;{ }^{1} \mathrm{H}$ NMR (500 MHz, DMSO- $\left.d_{6}\right): \delta 2.0 \mathrm{ppm}$ $\left(\mathrm{CH}_{3}-\mathrm{C}=\mathrm{O}\right), \delta 4.35 \mathrm{ppm}\left(\mathrm{N}^{+} \mathrm{CH}_{3}\right), 8.31 \mathrm{ppm}$ (triazole-5-H); FT-IR (thin film): $\nu 3417$ (stretching vibration of $\mathrm{OH}$ ), $\nu 2956$ and 2881 (stretching vibration of $\mathrm{C}-\mathrm{H}$ in methyl), $\nu 1739(\mathrm{C}=\mathrm{O}$ of acetyl), $\nu 790$ (C-H of triazole).

5b. Yield: $94.1 \% ;{ }^{1} \mathrm{H}$ NMR (500 MHz, DMSO- $\left.d_{6}\right): \delta 2.0 \mathrm{ppm}$ $\left(\mathrm{CH}_{3}-\mathrm{C}=\mathrm{O}\right), \delta 2.76 \mathrm{ppm}\left(\mathrm{OH}-\mathrm{CH}_{2}-\mathrm{CH}_{2}\right), \delta 4.35 \mathrm{ppm}\left(\mathrm{N}^{+} \mathrm{CH}_{3}\right)$; $\delta 8.27 \mathrm{ppm}$ (triazole-5-H); FT-IR (thin film): $\nu 3417$ (stretching 
vibration of $\mathrm{OH}$ ), $\nu 2962$ and 2877 (stretching vibration of $\mathrm{C}-\mathrm{H}$ in methyl), $\nu 1743(\mathrm{C}=\mathrm{O}$ of acetyl), $\nu 798$ (C-H of triazole).

5c. Yield: $73.5 \% ;{ }^{1} \mathrm{H}$ NMR (500 MHz, DMSO- $\left.d_{6}\right): \delta 1.84 \mathrm{ppm}$ $\left(\mathrm{OH}-\mathrm{CH}_{2}-\mathrm{CH}_{2}-\mathrm{CH}_{2}\right), \delta 2.04 \mathrm{ppm}\left(\mathrm{CH}_{3}-\mathrm{C}=\mathrm{O}\right), \delta 2.96 \mathrm{ppm}(\mathrm{OH}-$ $\left.\mathrm{CH}_{2}-\mathrm{CH}_{2}\right), \delta 4.23 \mathrm{ppm}\left(\mathrm{N}^{+} \mathrm{CH}_{3}\right), \delta 8.29 \mathrm{ppm}$ (triazole-5-H); FT-IR (thin film): $\nu 3409$ (stretching vibration of $\mathrm{OH}$ ), $\nu 2962$ and 2881 (stretching vibration of $\mathrm{C}-\mathrm{H}$ in methyl), $\nu 1743$ ( $\mathrm{C}=\mathrm{O}$ of acetyl), $\nu 790$ (C-H of triazole).

5d. Yield: $75.8 \% ;{ }^{1} \mathrm{H}$ NMR (500 MHz, DMSO- $\left.d_{6}\right): \delta 1.55 \mathrm{ppm}$ $\left(\mathrm{OH}-\mathrm{CH}_{2}-\mathrm{CH}_{2}-\mathrm{CH}_{2}-\mathrm{CH}_{2}\right), \delta 1.73 \mathrm{ppm}\left(\mathrm{OH}-\mathrm{CH}_{2}-\mathrm{CH}_{2}-\mathrm{CH}_{2}\right)$, $\delta 2.0 \mathrm{ppm}\left(\mathrm{CH}_{3}-\mathrm{C}=\mathrm{O}\right), \delta 2.88 \mathrm{ppm}\left(\mathrm{OH}-\mathrm{CH}_{2}-\mathrm{CH}_{2}\right), \delta 4.23 \mathrm{ppm}$ $\left(\mathrm{N}^{+} \mathrm{CH}_{3}\right) ; \delta 8.26 \mathrm{ppm}$ (triazole-5-H); FT-IR (thin film): $\nu 3424$ (stretching vibration of $\mathrm{OH}), \nu 2958$ and 2881 (stretching vibration of $\mathrm{C}-\mathrm{H}$ in methyl), $\nu 1743(\mathrm{C}=\mathrm{O}$ of acetyl), $\nu 802(\mathrm{C}-\mathrm{H}$ of triazole).

\subsection{Radical scavenging ability assay}

DPPH-radical scavenging ability assay. The DPPH scavenging properties of the products were evaluated by the following method: ${ }^{1}$ the test compound and $2 \mathrm{~mL} \mathrm{DPPH}$ solution $\left(180 \mu \mathrm{mol} \mathrm{L}^{-1}\right)$ in ethanol was incubated in a water bath at $25^{\circ} \mathrm{C}$ for $30 \mathrm{~min}$. Then, the absorbance of the remained DPPH radical was measured at $517 \mathrm{~nm}$ against a blank. Three replicates for each sample were tested and the scavenging effect was calculated using the following equation:

$$
\begin{aligned}
\text { Scavenging effect }(\%)= & {\left[1-\frac{A_{\text {sample } 517 \mathrm{~nm}}-A_{\text {control } 517 \mathrm{~nm}}}{A_{\text {blank } 517 \mathrm{~nm}}}\right] } \\
& \times 100 \%
\end{aligned}
$$

where $A_{\text {control }} 517 \mathrm{~nm}$ is the absorbance of the control (ethanol instead of DPPH for each concentration) and $A_{\text {blank }} 517 \mathrm{~nm}$ is the absorbance of the blank (distilled water instead of the sample). The antioxidant activity of test compound was expressed as $\mathrm{IC}_{50}$, which was defined as the concentrations of test compound required for inhibition of the formation of DPPH radical by $50 \%$. Vitamin C was used as a positive control.

Superoxide-radical scavenging ability assay. The superoxide radical scavenging ability was assessed following Xing's method with minor modification. ${ }^{9}$ Involving the test compound, $30 \mathrm{M}$ phenazine mothosulfate (PMS), $338 \mathrm{M}$ nicotinamide adenine dinucleotide reduced (NADH), and $72 \mathrm{M}$ nitro blue tetrazolium (NBT) in Tris-HCl buffer (16 mM, pH 8.0), the reaction mixture was incubated at $25{ }^{\circ} \mathrm{C}$ for $5 \mathrm{~min}$. The absorbance was read at $560 \mathrm{~nm}$ against blank. Three replicates for each sample were tested and the capability of scavenging superoxide radical was calculated using the following equation:

$$
\begin{aligned}
\text { Scavenging effect }(\%)= & {\left[1-\frac{A_{\text {sample } 560 \mathrm{~nm}}-A_{\text {control } 560 \mathrm{~nm}}}{A_{\text {blank } 560 \mathrm{~nm}}}\right] } \\
& \times 100 \%
\end{aligned}
$$

where $A_{\text {control }} 560 \mathrm{~nm}$ is the absorbance of the negative control (distilled water instead of NADH for each concentration) and $A_{\text {blank }} 560 \mathrm{~nm}$ is the absorbance of the blank (distilled water instead of the samples). The superoxide radical-scavenging activity was expressed as the $\mathrm{IC}_{50}$ value. Vitamin $\mathrm{C}$ was used as a positive control.
Hydroxyl-radical scavenging ability assay. The test of hydroxyl-radical scavenging ability was carried out according to Liu's method with minor modification. ${ }^{20}$ The reaction mixture, a total volume of $4.5 \mathrm{~mL}$, containing the samples of inulin, $4 \mathrm{a}-$ $4 d$ or $5 \mathbf{a}-5 \mathbf{d}(0.045,0.09,0.18,0.36$, and $0.72 \mathrm{~mL})$, were incubated with EDTA-Fe ${ }^{2+}(220 \mu \mathrm{M})$, safranine $\mathrm{O}(0.23 \mu \mathrm{M})$, and $\mathrm{H}_{2} \mathrm{O}_{2}(60 \mu \mathrm{M})$ in potassium phosphate buffer $(150 \mathrm{mM}, \mathrm{pH} 7.4)$ for $30 \mathrm{~min}$ at $37{ }^{\circ} \mathrm{C}$. The absorbance of the mixture was measured at $520 \mathrm{~nm}$. In the blank, samples were substituted with distilled water. Meanwhile, in the negative control, $\mathrm{H}_{2} \mathrm{O}_{2}$ was substituted with potassium phosphate buffer. Three replicates for each sample were tested. The capability of scavenging hydroxyl radicals was computed using the following equation:

$$
\text { Scavenging effect }(\%)=\frac{A_{\text {sample } 520 \mathrm{~nm}}-A_{\text {blank } 520 \mathrm{~nm}}}{A_{\text {control } 520 \mathrm{~nm}}-A_{\text {blank } 520 \mathrm{~nm}}} \times 100 \%
$$

where $A_{\text {blank }} 520 \mathrm{~nm}$ is the absorbance of the blank at $520 \mathrm{~nm}$; $A_{\text {sample } 520 \mathrm{~nm}}$ is the absorbance of the sample at $520 \mathrm{~nm}$; $A_{\text {control } 520 \mathrm{~nm}}$ is the absorbance of the control at $520 \mathrm{~nm}$. The antioxidant activity of test compounds was expressed as $\mathrm{IC}_{50}$. Vitamin C was used as a positive control.

\subsection{Antifungal assays}

Antifungal assays were performed by following the plate growth rate method described by Guo et al..$^{28}$ Briefly, the compounds (inulin, 4a-4d, and 5a-5d) were dispersed in distilled water at $5.0 \mathrm{mg} \mathrm{mL}{ }^{-1}$. Then, each solution was added to sterilized potato dextrose agar to give a final concentration of $0.1,0.5$, and $1.0 \mathrm{mg} \mathrm{mL}{ }^{-1}$. After the mixture was cooled in the plate $(6.0 \mathrm{~cm}$ diameter), $5.0 \mathrm{~mm}$ diameter of fungi mycelium was transferred to the test plate and incubated at $27^{\circ} \mathrm{C}$ for $2-3$ days. When fungi mycelium reached the edges of control plate (without the presence of samples), the antifungal index was calculated as follows:

$$
\text { Antifungal index }(\%)=\left(1-D_{\mathrm{a}} / D_{\mathrm{b}}\right) \times 100
$$

where $D_{\mathrm{a}}$ is the diameter of growth zone in test plate and $D_{\mathrm{b}}$ is the diameter of the growth zone in control plate. Each experiment was performed in three replicates, and the data were shown as mean $\pm \mathrm{SD}^{29}$

\section{Results and discussion}

\subsection{Chemical syntheses and characterization}

Each step of synthesis was followed by FT-IR and ${ }^{1} \mathrm{H}$ NMR spectroscopy measurements. The FT-IR and ${ }^{1} \mathrm{H}$ NMR spectra of intermediate products, compound $\mathbf{4 a - 4 d}$, and $\mathbf{5 a} \mathbf{-} \mathbf{- 5 d}$ are shown in Fig. 1 and 2 respectively.

C-6-Br inulin derivative was synthesized firstly by the reaction between the primary hydroxyls with NBS (Scheme 1), as NBS and $\mathrm{Ph}_{3} \mathrm{P}$ could selectively replace primary hydroxyl groups of polysaccharide with bromine. ${ }^{8}$ Then the secondary hydroxyls of the C6-Br inulin derivative were protected by acetic anhydride to bring hydrophobic groups into inulin backbone (2). The azidation of compound 2 could be conveniently achieved through a nucleophilic substitution at C-6 with sodium azide to get C-6-azido inulin derivative (3). The introduction of hydrophobic groups 


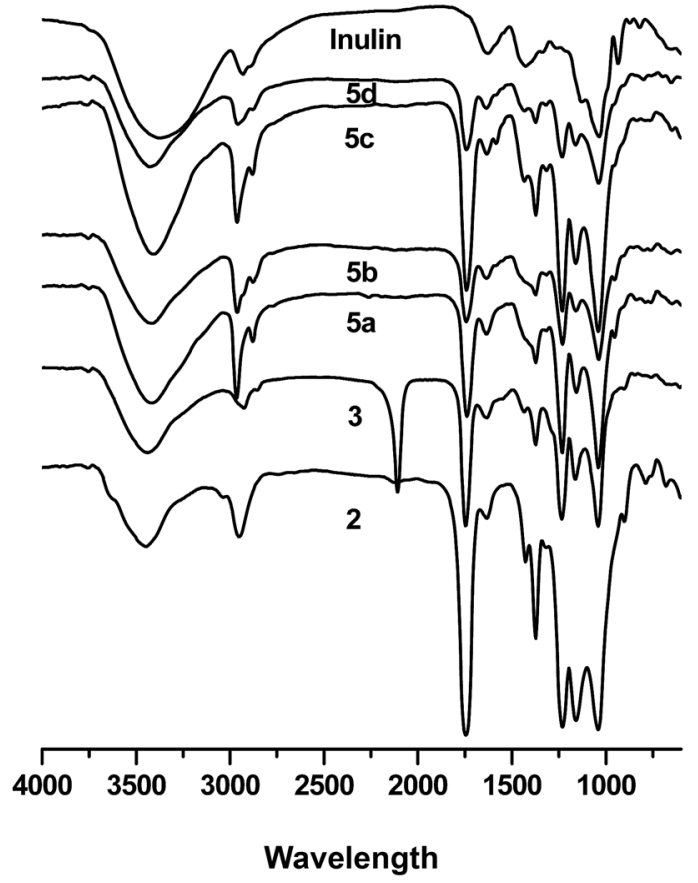

Fig. 1 FT-IR spectra of intermediate products and inulin derivatives $5 a-5 d$.

could effectively reduce the water solubility of inulin derivative (2 and 3), which facilitated the removal of inorganic salt and acetic anhydride by simply washing the products with water. In the spectrum of compound 3, characteristic peak of C-6-azido is observed at $2105 \mathrm{~cm}^{-1}$, and a strong peak at $1743 \mathrm{~cm}^{-1}$ was assigned to the vibration of the $\mathrm{C}=\mathrm{O}$ bonds of the acetyl ester (Fig. 1). In the ${ }^{1} \mathrm{H}$ NMR spectrum of compounds 2 and 3 (Fig. 2), the signals at 3.34-5.33 ppm were assigned to the protons of inulin. New signals, which appear at $2.01 \mathrm{ppm}$, could be assigned to the protons of $\mathrm{CH}_{3}-\mathrm{C}=\mathrm{O}$ (Fig. 2).

As long as we got C-6-azido inulin derivative (3), the 'click chemistry' could be performed in an elegant way with terminal alkynes to synthesize inulin derivative bearing 1,2,3-triazole. The peak at $2105 \mathrm{~cm}^{-1}$ in compound 3 spectrum disappears when the C-6-azido in compound 3 was transformed to 1,2,3triazoles and a new absorption band at about 794-789 $\mathrm{cm}^{-1}$ appears (Fig. 1). The appearance of the proton in 1,2,3-triazole at 7.72-7.83 ppm further proved the successful 'click reaction'. Besides, the new chemical shift at $2.77 \mathrm{ppm}$ (in 4b), 1.72 and $2.63 \mathrm{ppm}$ (in 4c), 1.42, 1.61, and $2.35 \mathrm{ppm}$ (in 4d), were assigned to the rest of methylenes.

Subsequently, alkylation of 1,2,3-triazolyl inulin derivative (4) was conducted by reacting with iodomethane in DMSO. The ${ }^{1} \mathrm{H}$ NMR spectrum of $\mathbf{5}$ corroborated the quaternization reaction through the disappearance of the peak, corresponding to the proton of the 1,2,3-triazole group (initially present at 7.72$7.83 \mathrm{ppm}$ in DMSO- $d_{6}$ ) and the quantitative appearance of new signals for the 1,2,3-triazolium proton and the $N-3$ methyl protons of the quaternizing group at 8.26-8.31 ppm and 4.23-4.35 ppm, respectively. ${ }^{21}$

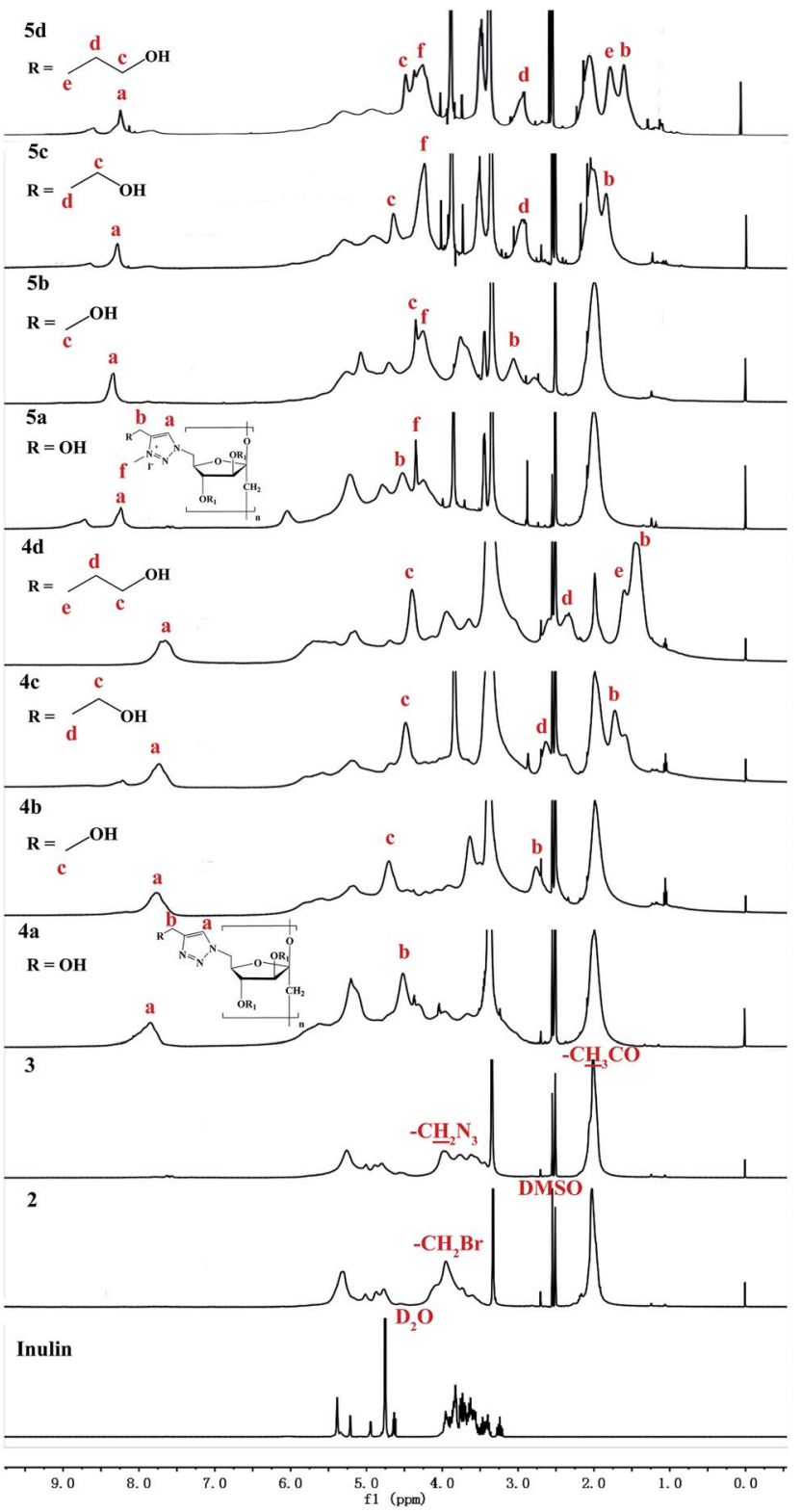

Fig. $2{ }^{1} \mathrm{H}$ NMR spectra of intermediate products and inulin derivatives.

\subsection{Solubility of the inulin derivatives}

Inulin has good water solubility. As the introduction of acetyl greatly reduced the water solubility of the inulin derivatives, hydrophobic 6-azido-6-deoxyinulin (3) exhibited worse water solubility. After "click reaction" between azido and terminal alkynes, 1,2,3-triazole was formed in inulin backbone. Because of the hydrophilic moiety at the end of the molecular chains, triazole enabled inulin derivative (4) with better water solubility. After the quaternization, the water solubility of inulin derivative (5) was further improved. Therefore, compounds 4 and 5 showed favourable water solubility, and their aqueous solutions could be prepared at $0.1-1.0 \mathrm{mg} \mathrm{mL}^{-1}$ at room temperature. 


\subsection{Radical scavenging activity}

As metabolic products of human body, free radical damage is of great threat to the health. ${ }^{22}$ Free radical, including hydroxyl radicals and superoxide anion, are normally generated in human body and scavenged by antioxidant defences system when free radical remains at physiological concentrations. ${ }^{23}$ Oxidative stress resulting from the toxic effects of free radicals on tissue plays an important role in the pathogenesis of various neurodegenerative diseases such as Alzheimer's disease, Parkinson's disease, and ischemic-reperfusion injury. ${ }^{\mathbf{2 4}}$ Free radical can also cause pathological damages like cancer disease, diabetes, atherosclerosis, coronary heart disease, and many other diseases associated with aging to the organism, and lead to harmful alterations in foods and pharmaceutical industry. ${ }^{20,25}$ It is of great interest among researchers to develop antioxidant supplements to help the human body reduce oxidative scratch. Moreover, restrictions over the use of synthetic antioxidants butyl hydroxyl anisd (BHA) and butylated hydroxytoluene (BHT) in food further strengthen the concept of using naturally occurring compounds as antioxidants. ${ }^{26}$ In order to study the effect of those chemical modifications mentioned above on the biological activity of inulin, it is essential to evaluate whether these compounds are able to scavenge the free radicals using different assay systems such as the DPPH radical-scavenging, superoxide radical-scavenging, and hydroxyl radical-scavenging assay.

The DPPH radical scavenging activity of inulin and its related derivatives was tested by their ability to bleach the stable radical DPPH (Fig. 3). This assay provided information on the reactivity of the compounds with a stable free radical. Because of the odd electron, DPPH shows a strong absorption band at $517 \mathrm{~nm}$ in visible spectroscopy (deep violet color). As this electron becomes paired off in the presence of a free radical scavenger, the absorption vanishes, and the resulting decolorization is stoichiometric with respect to the number of electrons taken up. ${ }^{24}$ Vitamin E, a reference drug, exhibited scavenging activity with $\mathrm{IC}_{50}$ value of $24.5 \mu \mathrm{M}\left(\mathrm{IC}_{50} 0.01 \mathrm{mg} \mathrm{mL}{ }^{-1}\right) \cdot{ }^{24}$ As a positive control, Vitamin $\mathrm{C}$ was tested with $\mathrm{IC}_{50}<0.1 \mathrm{mg} \mathrm{mL}{ }^{-1}$. Inulin showed relatively weak scavenging activity against DPPH radical, and the scavenging index was $19.03 \%$ at $1.6 \mathrm{mg} \mathrm{mL}^{-1}$. In this test the synthesized inulin derivatives (4a-4d and 5a-5d)

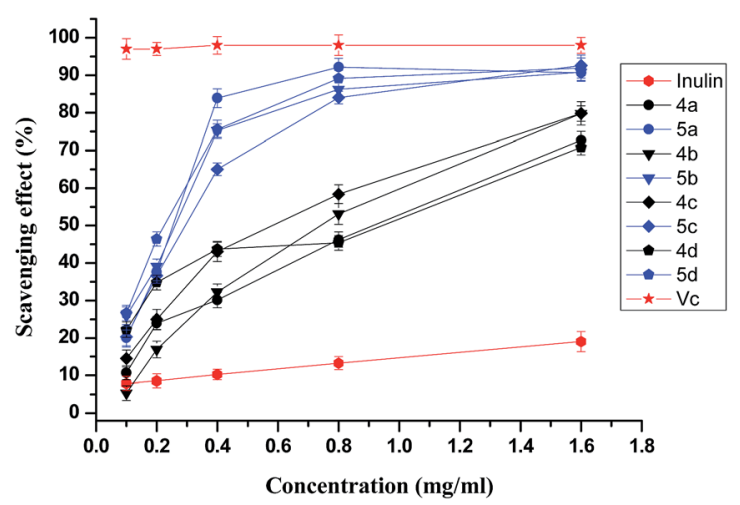

Fig. 3 DPPH-radical scavenging ability of inulin and inulin derivatives. gave much stronger DPPH-radical scavenging ability compared with inulin. Meanwhile, compounds 5a-5d ( $\mathrm{IC}_{50}$ 0.21$0.29 \mathrm{mg} \mathrm{mL} \mathrm{mL}^{-1}$ ) was more efficient than compound 4a-4d $\left(\mathrm{IC}_{50} 0.58-0.95 \mathrm{mg} \mathrm{mL}^{-1}\right)$.

The superoxide radical-scavenging activity of inulin and derivatives synthesized was also evaluated based on their ability to quench the superoxide radical generated from the PMS/ $\mathrm{NADH}$ reaction (Fig. 4). This assay provides information on the reactivity of test compounds with superoxide free radicals, independently of any enzymatic activity. The generation of superoxide anions was markedly inhibited by Vitamin $\mathrm{C}$ with an $\mathrm{IC}_{50}$ value of $0.02 \mathrm{mg} \mathrm{mL}{ }^{-1}$, and superoxide dismutase (SOD) with an $\mathrm{IC}_{50}$ value of 3.5 units per $\mathrm{mL}^{24}$ Inulin, $\mathbf{4 a - 4 d}$, and $5 \mathbf{a}-$ 5d inhibited superoxide anion formation in a concentrationdependent manner, but 5a-5d showed more potent scavenging activity $\left(\mathrm{IC}_{50}<0.01 \mathrm{mg} \mathrm{mL}{ }^{-1}\right)$, followed by $\mathbf{4 a - 4 d}\left(\mathrm{IC}_{50}\right.$ of 4a-4c $0.02-0.09 \mathrm{mg} \mathrm{mL} \mathrm{m}^{-1}, \mathrm{IC}_{50}$ of $4 \mathrm{~d}<0.01 \mathrm{mg} \mathrm{mL}^{-1}$ ), and inulin ( $\left.\mathrm{IC}_{50} 1.34 \mathrm{mg} \mathrm{mL}^{-1}\right)$, respectively.

Fig. 5 shows the hydroxyl radical-scavenging ability of inulin and synthesized derivatives at various concentrations. Mannitol, a classical hydroxyl radical scavenger, can significantly inhibited deoxyribose degradation with an $\mathrm{IC}_{50}$ value of $4.6 \mathrm{mM} .{ }^{24}$ The hydroxyl-radical scavenging ability of inulin and Vitamin $\mathrm{C}$ is weak, and the maximum inhibitory activity in the test concentration range $\left(0.1-1.6 \mathrm{mg} \mathrm{mL}^{-1}\right)$ is $48 \%$ and $30 \%$ respectively. The hydroxyl-radical scavenging ability of inulin is weak, and the maximum inhibitory activity in the test concentration range $\left(0.1-1.6 \mathrm{mg} \mathrm{mL}^{-1}\right)$ is $48 \%$. The synthesized inulin derivatives (4a-4d and 5a-5d) also show much stronger hydroxyl-radical scavenging ability compared with inulin, and
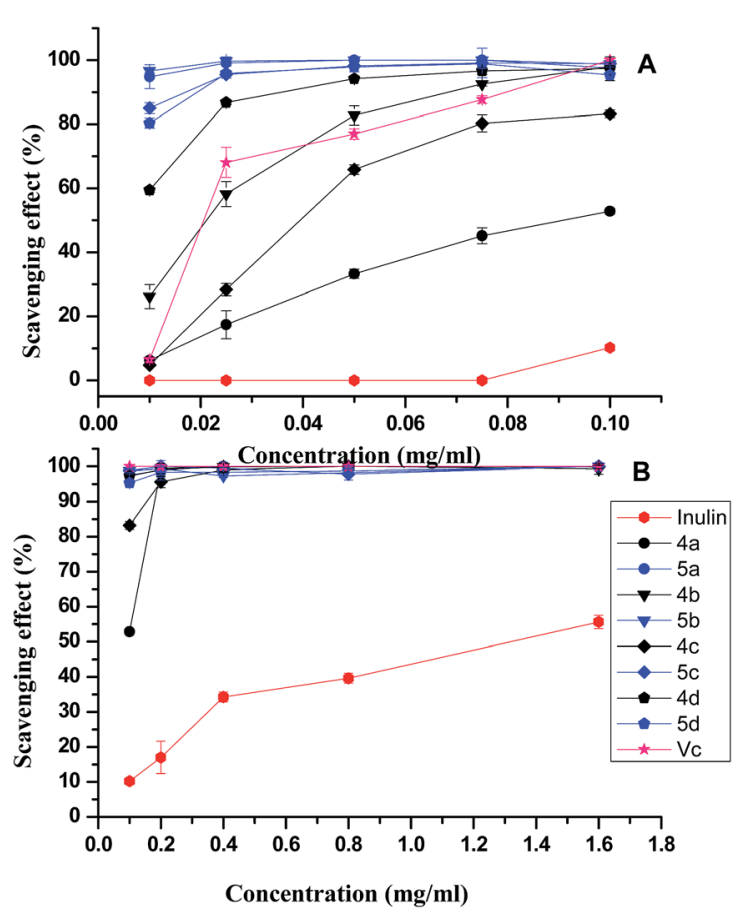

Fig. 4 Superoxide-radical scavenging ability of inulin and inulin derivatives at different concentrations: (A) $0.01-0.1 \mathrm{mg} \mathrm{mL}^{-1}$; (B) $0.1-$ $1.6 \mathrm{mg} \mathrm{mL}^{-1}$. 


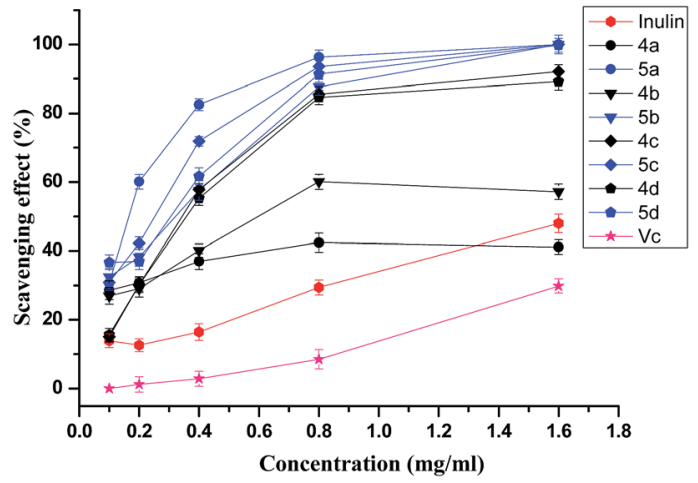

Fig. 5 Hydroxyl-radical scavenging ability of inulin and inulin derivatives.

suppressed hydroxyl-radical in a concentration-dependent manner. The inhibitory activity was observed in the following order: 5a-5d $\left(\mathrm{IC}_{50} 0.16-0.32 \mathrm{mg} \mathrm{mL}{ }^{-1}\right)>\mathbf{4 a - 4 d}\left(\mathrm{IC}_{50} 0.34-\right.$ $0.59 \mathrm{mg} \mathrm{mL}^{-1}$ ) > inulin.

On the basis of $\mathrm{IC}_{50}$, it is obvious that inulin derivatives with triazole or triazolium show much better antioxidant activity due to the introduction of functional groups - triazole groups. Free radical chain reactions may be inhibited by adding preventive antioxidants that retard the formation of free radicals or stabilize free radicals. ${ }^{27,28}$ Owing to the slightly polarized nature of the $\mathrm{C}(5)-\mathrm{H}$ bond, 1,2,3-triazoles have gained recognition as excellent hydrogen donors, ${ }^{29}$ which can form stable free radicals. Meanwhile, the conjugated double bonds allow electron delocalisation across the molecule thus stabilize the radical. ${ }^{26}$ Furthermore, it is apparent that the inulin derivatives with triazolium group (5a-5d) own better hydroxyl-radical scavenging ability. Since the $\mathrm{C}(5)-\mathrm{H} \cdots \mathrm{A}^{-}$binding ability is strongly enhanced by converting the triazole unit into a triazolium cation, the latter is expected to be a more efficient anion captor, ${ }^{29}$ which may help stabilize the free radicals form. On the other hand, other factors such as the surface activity affected by the structure of polymers and the different mechanisms involved in the radical antioxidant reactions in different systems may also affect the capacity of test compounds to react with and quench different radicals. The scavenging effect on DPPH radicals and superoxide radicals represents direct radical-scavenging activity. However, in the hydroxyl radical scavenging assay, hydroxyl radicals are generated by the Fenton reaction and the inhibition could be attributed to the inhibition of radicals or the $\mathrm{Fe}^{2+}$ chelating effect of the test compounds. ${ }^{24}$

Many polysaccharides themselves have relatively weak antioxidant activity. The hydroxyl radical scavenging index of starch and hyaluronan was $22 \%$ and $40 \%$ at $1.6 \mathrm{mg} \mathrm{mL}^{-1}$ respectively, ${ }^{30}$ which is weaker than that of inulin. Chitosan, one of the most important polysaccharide, has stronger scavenging activity on hydroxyl radicals with $\mathrm{IC}_{50} 0.48 \mathrm{mg} \mathrm{mL}{ }^{-1} \cdot{ }^{31}$ Recently, chemical modification of polysaccharides is increasingly reported for its potential of improving the biological activity of polysaccharides. Fan reported antioxidant activity of silk peptides grafted carboxymethyl chitosan, and the highest scavenging activity of
DPPH was $24.86 \%, 91 \%$ of hydroxyl radical and $36.8 \%$ of $\mathrm{H}_{2} \mathrm{O}_{2}$ at the concentration of $0.5-2.5 \mathrm{mg} \mathrm{mL}{ }^{-1} \cdot{ }^{32}$ Double quaternized chitosan derivatives showed better scavenging ability than chitosan, with more than $90 \%$ scavenging indices against hydroxyl radicals and DPPH radicals at $1.6 \mathrm{mg} \mathrm{mL} \mathrm{m}^{-1} \cdot{ }^{33}$ Tan synthesized aminopyridinium-grafted starch derivative and found antioxidant property of synthesized starch derivatives was affected by the different positions and the number of amino groups on pyridinium rings. ${ }^{34}$ The experimental data above and related literature demonstrated that the chemical modification of polysaccharides was conducive to improving the free radical scavenging activity of them.

\subsection{Antifungal activity}

Plant pathogenic fungi negatively affect a large number of important fruits and vegetables, and limit crop production worldwide, especially in developing countries. For example, the premature plant death caused by $C$. lagenarium can result in a yield loss of $6-48 \% .^{35}$ Control of these plants-threatening fungi could benefit the production of related vegetables, fruits, and crops. In this paper, two common harmful Gibberella zeae and $C$. lagenarium were selected to estimate the antifungal activity of inulin and the synthesized inulin derivatives (4a-4d and 5a-5d). The results are shown in Fig. 6 and 7.

As seen in Fig. 6, inulin does not inhibit the growth of Gibberella zeae at the tested concentrations. Compared with inulin, after the introduction of triazole groups, compound 4a-4d have evident antifungal activities against Gibberella zeae and the inhibitory indices of compound $\mathbf{4 a}-\mathbf{4 d}$ are $9.82 \%, 25.65 \%$, $29.73 \%$, and $20.21 \%$ at $1.0 \mathrm{mg} \mathrm{mL}^{-1}$, respectively. Meanwhile, the inhibitory indices of all the samples ascend with the increasing concentration. It is obvious that inulin derivatives containing triazole (4a-4d) show much better antifungal activity due to the introduction of functional groups - thiazolyl groups. Furthermore, inulin derivatives containing triazolium (5a-5d) exhibit higher inhibitory indices than those of inulin derivatives containing triazoles (4a-4d), and the inhibitory indices of compound $4 \mathbf{a}-4 \mathrm{~d}$ are $43.10 \%, 61.65 \%, 67.57 \%$, and $82.56 \%$ at $1.0 \mathrm{mg} \mathrm{mL}{ }^{-1}$, respectively. These data suggest that stronger antifungal activity of inulin derivative (5a-5d) may mainly benefit from the alkylation of 1,2,3-triazole. The cationic triazolium may interact with the anionic components on the cell

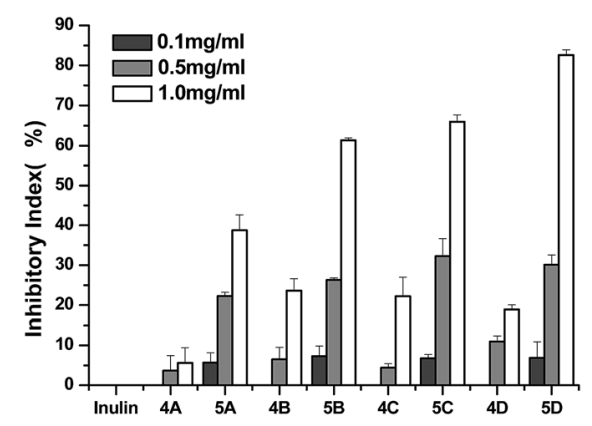

Fig. 6 The antifungal activity of inulin and inulin derivatives against Gibberella zeae. 


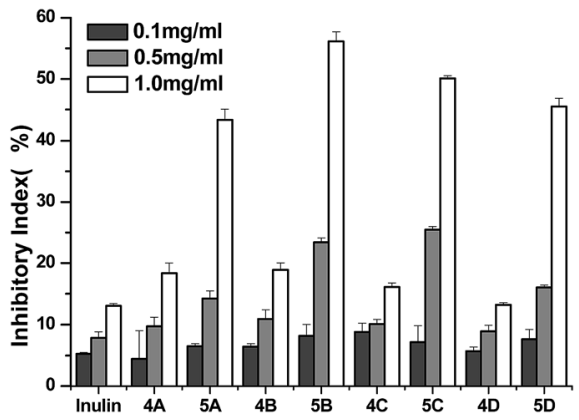

Fig. 7 The antifungal activity of inulin and inulin derivatives against $C$. lagenarium.

wall of fungi, such as glucan, mannan, proteins, and lipids; this leads to the formation of an impervious layer around the cell. The layer could prevent the transportation of essential nutrients, such as glucose, into the cell and may also disturb the cell wall and, thereby, cause severe leakage of the cell constituents and, ultimately, cell death. ${ }^{18}$

Fig. 7 shows the antifungal activity of inulin and all the derivatives against $C$. lagenarium. All the samples show antifungal activity against $C$. lagenarium, and the inhibitory indices of them mount up with increasing concentration. The antifungal activity of inulin is weak against $C$. lagenarium and the inhibitory index is $6.0 \%$ at $1.0 \mathrm{mg} \mathrm{mL}^{-1}$. The inhibitory indices of inulin derivatives containing triazoles (4a-4d) are $20.0 \%$, $20.2 \%, 16.6 \%$, and $23.2 \%$ at $1.0 \mathrm{mg} \mathrm{mL}^{-1}$, respectively. And the inhibitory indices of inulin derivatives containing triazolium (5a-5d) are $45.31 \%, 57.93 \%, 50.42 \%$, and $46.93 \%$ at $1.0 \mathrm{mg} \mathrm{mL}^{-1}$, respectively. Similar to the antifungal activity against Gibberella zeae, eight inulin derivatives give much stronger antifungal activity than unmodified inulin, and the inhibitory indices of inulin derivatives containing triazolium (5a-5d) are higher than those of inulin derivatives containing triazoles $(\mathbf{4 a - 4 d})$ at the same concentration. The results further confirmed that triazolium groups grafted into the synthesized inulin derivatives contributed a lot to the antifungal action and consequently increase the antifungal activity of them. Previous studies had proven that quaternized chitosan had a higher cationic charge than chitosan, which were more prone to interaction with anionic components of the cell wall of fungi. As a result, they would have had stronger antifungal activities. ${ }^{18}$

\section{Conclusions}

In this paper, we have proposed a straightforward synthetic route to a new class of inulin derivatives possessing 1,2,3-triazolium charged units by associating "click reaction" with efficient 1,2,3-triazole quaternization. The radical scavenging activity against three kinds of free radicals and antifungal activity against two kinds of phytopathogens were estimated. All the inulin derivatives showed good solubility in water, and exhibited higher radical scavenging activity and antifungal activity than inulin. Moreover, the synthesized inulin derivative bearing 1,2,3-triazolium showed more significant biological activity than inulin derivative with 1,2,3-triazole and inulin. The mechanism of the obtained biological activity was also discussed. The 1,2,3-triazolium would be a more efficient anion captor than triazole after quaternarization, which might help stabilize the free radicals form. Meanwhile, the 1,2,3-triazolium had a higher cationic charge, which were more prone to interaction with anionic components on fungi cell wall. Further study will be carried out to ascertain this hypothesis. The experiment data demonstrated that the chemical modification of inulin with 1,2,3-triazolium functional groups was conducive to improving the biological activity of inulin. These findings mentioned above bring further evidence that inulin derivatives are active and have the potential of becoming alternatives of free radical scavenger.

\section{Conflicts of interest}

There are no conflicts to declare.

\section{Acknowledgements}

We thank the National Natural Science Foundation of China (41576156), Shandong Province Science and Technology Development Plan (2015GSF121045 and ZR2017BD015), Yantai Science and Technology Development Plan (2015ZH078), and Technology Research Funds Projects of Ocean (No. 2015050223) for financial support of this work.

\section{Notes and references}

1 Y. Hu, J. Zhang, C. Yu, Q. Li, F. Dong, G. Wang and Z. Guo, Int. J. Biol. Macromol., 2014, 70, 44-49.

2 W. Tan, J. Zhang, F. Luan, L. Wei, Y. Chen, F. Dong, Q. Li and Z. Guo, Int. J. Biol. Macromol., 2017, 102, 704-711.

3 W. Tan, Q. Li, L. Wei, P. Wang, Z. Gao, Y. Chen, F. Dong and Z. Guo, Mater. Sci. Eng., C, 2017, 76, 1048-1056.

4 Q. Li, C. Zhang, W. Tan, G. Gu and Z. Guo, Molecules, 2017, 22, 156-165.

5 J. Ahmed, L. Thomas, A. Taher and A. Joseph, Carbohydr. Polym., 2016, 152, 639-647.

6 S. Adak and R. Banerjee, Carbohydr. Polym., 2016, 150, 359368.

7 L. Fan, J. Yang, H. Wu, Z. Hu, J. Yi, J. Tong and X. Zhu, Int. J. Biol. Macromol., 2015, 79, 830-836.

8 F. Dong, J. Zhang, C. Yu, Q. Li, J. Ren, G. Wang, G. Gu and Z. Guo, Bioorg. Med. Chem. Lett., 2014, 24, 4590-4593.

9 J. Ren, J. Liu, F. Dong and Z. Guo, Carbohydr. Polym., 2011, 83, 1240-1244.

10 J. M. Ren, P. B. Wang, F. Dong, Y. Feng, D. J. Peng and Z. Y. Guo, Carbohydr. Polym., 2012, 87, 1744-1748.

11 X. Ouyang, X. Chen, E. L. Piatnitski, A. S. Kiselyov, H. Y. He, Y. Mao, V. Pattaropong, Y. Yu, K. H. Kim, J. Kincaid, L. Smith 2nd, W. C. Wong, S. P. Lee, D. L. Milligan, A. Malikzay, J. Fleming, J. Gerlak, D. Deevi, J. F. Doody, H. H. Chiang, S. N. Patel, Y. Wang, R. L. Rolser, P. Kussie, M. Labelle and M. C. Tuma, Bioorg. Med. Chem. Lett., 2005, 15, 5154-5159. 
12 S. Eswaran, A. V. Adhikari and N. S. Shetty, Eur. J. Med. Chem., 2009, 44, 4637-4647.

13 H. Park, Y. J. Bahn and S. E. Ryu, Bioorg. Med. Chem. Lett., 2009, 19, 4330-4334.

14 Y. P. Hou, J. Sun, Z. H. Pang, P. C. Lv, D. D. Li, L. Yan, H. J. Zhang, E. X. Zheng, J. Zhao and H. L. Zhu, Bioorg. Med. Chem., 2011, 19, 5948-5954.

15 D. Abuo-Rahma Gel, M. Abdel-Aziz, E. A. Beshr and T. F. Ali, Eur. J. Med. Chem., 2014, 71, 185-198.

16 L. Liu, S. He, S. Zhang, M. Zhang, M. D. Guiver and N. Li, ACS Appl. Mater. Interfaces, 2016, 8, 4651-4660.

17 W. Tan, J. Zhang, F. Luan, L. Wei, Q. Li, F. Dong and Z. Guo, Int. J. Biol. Macromol., 2017, 101, 845-851.

18 J. Ren, J. Liu, R. Li, F. Dong and Z. Guo, J. Appl. Polym. Sci., 2012, 124, 2501-2507.

19 W. Tan, Q. Li, Z. Gao, S. Qiu, F. Dong and Z. Guo, Carbohydr. Polym., 2017, 157, 236-243.

20 J. Liu, H. Sun, F. Dong, Q. Xue, G. Wang, S. Qin and Z. Guo, Carbohydr. Polym., 2009, 78, 439-443.

21 R. Sood, M. M. Obadia, B. P. Mudraboyina, B. Zhang, A. Serghei, J. Bernard and E. Drockenmuller, Polymer, 2014, 55, 3314-3319.

22 Z. Peng, M. Liu, Z. Fang and Q. Zhang, Int. J. Biol. Macromol., 2012, 50, 1254-1259.

23 G.-H. Wu, T. Hu, Z.-Y. Li, Z.-L. Huang and J.-G. Jiang, Food Chem., 2014, 148, 351-356.
24 P. Mahakunakorn, M. Tohda, Y. Murakami, K. Matsumoto and H. Watanabe, Biol. Pharm. Bull., 2004, 27, 38-46.

25 D. Wei, W. Cheng, Y. Wei and L. Zhang, Glycoconjugate J., 2012, 29, 167-172.

26 M. A. Soobrattee, V. S. Neergheen, A. Luximon-Ramma, O. I. Aruoma and T. Bahorun, Mutat. Res., Fundam. Mol. Mech. Mutagen., 2005, 579, 200-213.

27 P.-J. Park, W.-K. Jung, K.-S. Nam, F. Shahidi and S.-K. Kim, J. Am. Oil Chem. Soc., 2001, 78, 651-656.

28 E. S. H. El Ashry, E. El-Rafey, N. Rezki, H. H. Abou-Elnaga, W. M. A. Bakry and Y. M. Boghdadi, J. Saudi Chem. Soc., 2014, 18, 443-449.

29 J. M. Aizpurua, R. M. Fratila, Z. Monasterio, N. PerezEsnaola, E. Andreieff, A. Irastorza and M. SagartzazuAizpurua, New J. Chem., 2014, 38, 474-480.

30 S. Yang, Z. Guo, F. Miao, Q. Xue and S. Qin, Carbohydr. Polym., 2010, 82, 1043-1045.

31 Z. Guo, H. Liu, X. Chen, X. Ji and P. Li, Bioorg. Med. Chem. Lett., 2006, 16, 6348-6350.

32 Y. A. Skorik, A. S. Kritchenkov, Y. E. Moskalenko, A. A. Golyshev, S. V. Raik, A. K. Whaley, L. V. Vasina and D. L. Sonin, Carbohydr. Polym., 2017, 166, 166-172.

33 L. Wei, Q. Li, W. Tan, F. Dong, F. Luan and Z. Guo, Molecules, 2017, 22, 501.

34 Z. G. W. Tan, Q. Chen, F. Dong and Q. Li, Starch, 2017, 69, 18.

35 Y. Chen and G. Dai, J. Sci. Food Agric., 2012, 92, 1937-1943. 